\title{
Mineral transfer between enamel and artificial saliva
}

\author{
Hitoshi Kurihara ${ }^{1}$, Tomoko Kataumi ${ }^{1}$, Kosuke Tanase ${ }^{1}$, Kosuke Eda ${ }^{1}$, Hidefumi Ikeda ${ }^{1}$, Takashi Ogihara ${ }^{1}$, Koji Watanabe $^{1}$ \\ and Shigeru Watanabe*1 \\ ${ }^{1}$ Department of Human Development \& Fostering. Division of Pediatric Dentistry, School of Dentistry Meikai University, Japan
}

\begin{abstract}
Objectives: The objective of this study was to clarify changes in enamel mineral density after immersion in pH-regulated artificial saliva as well as concentrations of calcium $(\mathrm{Ca})$ and phosphorous $(\mathrm{P})$ in artificial saliva.

Methods: Three segments of size 5-by-5 mm taken from the enamel surface of each of 15 selected bovine anterior teeth were prepared and coated with nail varnish, excluding the labial side. The specimens were immersed in $10 \mathrm{~mL}$ of artificial saliva $\left(0.7 \mathrm{mM} / \mathrm{L} \mathrm{CaCl}_{2}, 0.2 \mathrm{mM} / \mathrm{L} \mathrm{MgCl}, 4.0 \mathrm{mM} / \mathrm{L} \mathrm{KH}{ }_{2} \mathrm{PO}, 30.0 \mathrm{mM} / \mathrm{L} \mathrm{KCl}_{4}\right.$ $20.0 \mathrm{mM} / \mathrm{L}$ HEPES) and regulated at pH 7.0 or 5.5 by KOH for 10 days. Their average Hounsfield unit values (HUV) were measured from the enamel surface to a site $600 \mu \mathrm{m}$ in depth by using Micro CT. Further, concentrations of Ca and P in the artificial saliva before and after the immersion were measured. Subsequently, the specimens of the $\mathrm{pH} 5.5$ group were again immersed in artificial saliva regulated at $\mathrm{pH} 7.0$ for 10 days and the same measurements were carried out.

Results: Average HUVs of the pH 5.5 group showed significantly lower values than the ST group only at a layer $0-150 \mu \mathrm{m}$ in depth (p<0.01). The concentrations of $\mathrm{Ca}$ and $\mathrm{P}$ in the $\mathrm{pH} 5.5$ group showed significantly higher values after the immersion $(3.73 \pm 0.44),(12.37 \pm 0.41)$ than those before the immersion $(2.80 \pm 0.18)$, $(11.72 \pm 0.12)$. As a result of immersion of specimens of $\mathrm{pH} 5.5$ group in saliva of $\mathrm{pH} 7.0$, there was no significant change in mineral density in enamel and $\mathrm{Ca}$ and $\mathrm{P}$ in saliva.
\end{abstract}

Conclusion: It was confirmed that the mineral transfer between enamel and saliva in demineralization depends on the $\mathrm{pH}$ of saliva.

\section{Introduction}

It is possible to confirm mineral transfer between enamel and saliva by analyzing changes in mineral density in saliva [1]. On the other hand, few studies have been made on the aspect of increase and decrease in minerals on the enamel side, leaving the details unknown.

Even though the Transversal Micro Radiography (TMR) method [2] is generally used for evaluating tooth demineralization and remineralization by observing teeth segments using an X-ray Micro Analyzer, it is impossible to observe continuous change in demineralization due to limitation in preparation of specimens by this method. The Quantitative Light Induced Fluorescence (QLF) method is applicable for clinical evaluation for demineralization and remineralization in a non-destructive manner, but it is possible neither to measure a slight amount of demineralization for a short period of time nor to observe it by each depth [3]. On the contrary, Micro X-ray CT (Micro CT) with a property capable of sterically observing change in mineral density in small amounts by micro units has been used recently for measuring change in enamel mineral density [4] during early stage demineralization or enamel mineral density with developed dysplasia [5].

The objective of the study was to analyze changes in the concentration of $\mathrm{Ca}$ and $\mathrm{P}$ in artificial saliva and variation in mineral density on the enamel surface layer based on Micro CT using bovine teeth enamel and artificial saliva with regulated $\mathrm{pH}$ in order to clarify the actual conditions of mineral transfer between mineral and saliva.

\section{Materials and methods}

\section{Materials}

Polishing 15 bovine anterior teeth with a sandpaper (No. 400$600)$ moderately and taking tomographic images to be reconstructed by using Micro CT (SKYSCAN1172, SKYSCAN, Kontich, Belgium) with a tube voltage of $100 \mathrm{kVp}$ and tube current of $100 \mu \mathrm{A}$, the average Hounsfield unit value (HUV) of enamel from the surface to a site 600 $\mu \mathrm{m}$ in depth was measured [6]. In order to exclude teeth with larger inter-individual variability in HUV, a total of 10 of them were served for the experiment by eliminating 5 teeth with an SD exceeding the average value of 1 .

\section{Methods}

Analysis of specimens: Preparing three pieces of tooth tissue specimens, with a size of $5 \times 5 \times 5 \mathrm{~mm}$ including enamel surface on the labial side, from each selected bovine tooth, each specimen was immersed in $10 \mathrm{~mL}$ of artificial saliva separately within an incubator which was kept at $37 \square$ for 10 days after coating all surfaces other than the labial side of each specimen with nail varnish. Extracting all specimens from the artificial saliva 10 days after the immersion and removing the nail varnish with polish remover, tomographic images taken by using Micro CT under a condition of a tube voltage of $100 \mathrm{kVp}$ and tube current of $100 \mu \mathrm{A}$ was reconstructed and then, the average

Correspondence to: Shigeru Watanabe, Department of Human Development \& Fostering, Division of Pediatric Dentistry, School of Dentistry, Meikai University, 1-1 Keyakidai, Sakado, Saitama 350-0283, Japan, Tel: (+81) 49-279-2743, Fax: (+81) 49-279-2743, E-mail: shigeru@dent.meikai.ac.jp

Special Issue: Early Caries (Surbsurface Demineralization)

Shigeru Watanabe, DDS, PhD

Professor of Division of Pediatric Dentistry,

School of Dentistry, Meikai University, Japan

Published: April 12, 2017 
HUV of enamel from the surface at a site $600 \mu \mathrm{m}$ in depth was measured (Figure 1). In the subsequent remineralization experiment, the average HUV was measured similarly after immersing in remineralization solution regulated at pH7.0.

Artificial salivary constituent: Artificial saliva was prepared by a formulation ( $0.7 \mathrm{mM}$ of $\mathrm{CaCl}_{2}, 0.2 \mathrm{mM}$ of $\mathrm{MgCl}_{2}, 4.0 \mathrm{mM}$ of $\mathrm{KH}_{2} \mathrm{PO}_{4}$, $30.0 \mathrm{mM}$ of $\mathrm{KCl}$, and $20.0 \mathrm{mM}$ of HEPES) [7] commonly used for enamel remineralization experiments or the like while adjusting at $\mathrm{pH}$ 7.0 or 5.5 by potassium hydroxide. Specimens immersed in artificial saliva at $\mathrm{pH} 7.0$ and 5.5 were classified into a $\mathrm{pH} 7.0$ group and $\mathrm{pH} 5.5$ group respectively, with the control (ST) group which were immersed in neither $\mathrm{pH}$ of artificial saliva. Concentrations of $\mathrm{Ca}$ and $\mathrm{P}$ were measured just before immersing specimens as well as soon after 10 days of immersion. In the remineralization experiment, specimens immersed in artificial saliva at $\mathrm{pH} 5.5$ for 10 days were further immersed in $10 \mathrm{~mL}$ of artificial saliva at $\mathrm{pH} 7.0$ which was replaced by new saliva every two days, and concentrations of $\mathrm{Ca}$ and $\mathrm{P}$ were measured each time saliva was replaced. In the case of the ST group, four specimens of bovine anterior teeth enamel, of which HUVs had been measured by Micro CT after demineralization, were further immersed in ultrapure water regulated at $\mathrm{pH} 7.0$ for 5 days and their HUVs were measured.

Measurement of Ca concentration in artificial saliva: A calcium measurement kit (Calcium E- Test Wako/Wako Pure Chemical Industries Ltd., Japan) was used for measurement of Ca concentration. Consisting of a buffer solution (monoethanolamine buffer solution/pH 12.0), coloring test solution (methyl xylenol blue MXB, 8-quinolinol) and Ca standard solution, the Calcium E - Test Wako utilizes a reaction which appears to be blue by combining $\mathrm{Ca}$ with MXB under alkaline conditions. Preparing a calibration curve by using an Absorbance Microplate Reader, the $\mathrm{Ca}$ concentration was obtained based on absorbance of each sample.

Measurement of $\mathbf{P}$ concentration in artificial saliva: $A$ phosphorous measurement kit (Phosphor C- Test Wako/Wako Pure Chemical Industries Ltd., Japan) was used for measurement of Phosphorous concentration. Consisting of a coloring test solution (p-methylamino phenol sulfate, surfactant, surfactant, ammonium molybdate, sulfuric acid), and P standard solution, Phosphor C-Test Wako utilizes a reaction in which phosphomolybdic acid generated by combining $\mathrm{P}$ with molybdate appears to be blue in a form of molybdenum blue further reduced by p-methylamino phenol sulfate. Preparing a calibration curve by using an Absorbance Microplate Reader similarly to the case of Ca concentration, $\mathrm{P}$ concentration was obtained based on the absorbance of each sample.

Statistical processing: In terms of the comparison of measurement results, a Student's t-test was used for comparisons between two groups, and the 2-way ANOVA as well as Scheffe's method were used for those between more than two groups, regarding values with $\mathrm{p}<0.05$ to be significant.

\section{Results}

Changes in $\mathrm{Ca}$ and $\mathrm{P}$ concentrations before and after immersion of the specimens in artificial saliva at each $\mathrm{pH}$ for 10 days are shown in Table 1. Ca concentration in saliva regulated at $\mathrm{pH} 7.0$ was $1.73 \pm$ $0.44 \mathrm{mg} / \mathrm{dL}$ and $1.51 \pm 0.13 \mathrm{mg} / \mathrm{dL}$ before and after the immersion respectively, showing no significant difference between the two values. On the other hand, that in saliva regulated at pH 5.5 was $2.80 \pm 0.18 \mathrm{mg} /$

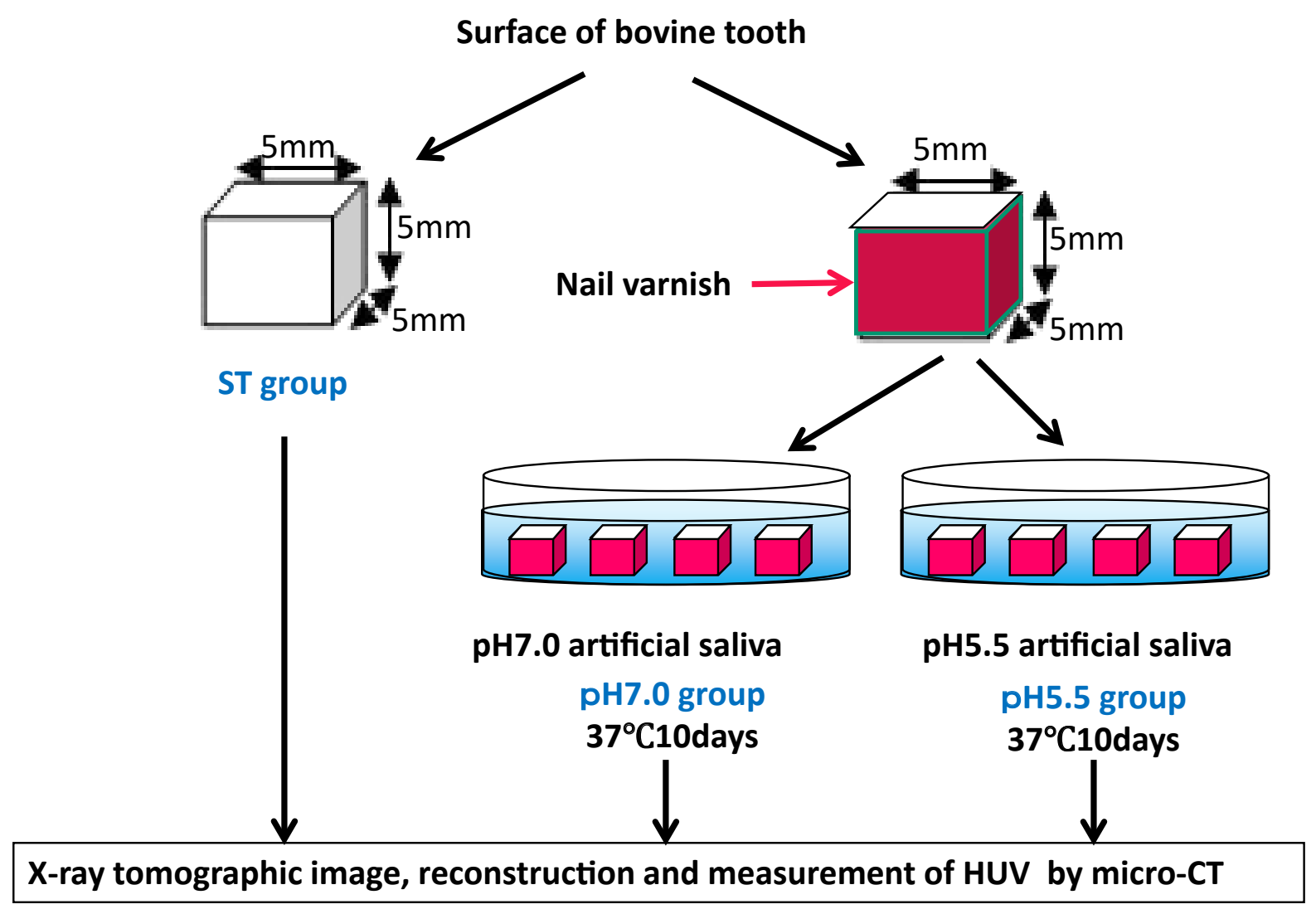

Figure 1. Method 
$\mathrm{dL}$ and $3.73 \pm 0.44 \mathrm{mg} / \mathrm{dL}$ before and after the immersion respectively, with significant increase after immersion recognized $(\mathrm{p}<0.05)$.

No significant difference was observed in the values of $\mathrm{P}$ concentration between before and after immersion in saliva regulated at $\mathrm{pH}$ 7.0. In the case of saliva regulated at $\mathrm{pH} 5.5$, the value after immersion $(12.37 \pm 0.41 \mathrm{mg} / \mathrm{dL})$ showed significant increase $(\mathrm{p}<0.01)$ compared with that before immersion $(11.72 \pm 0.12 \mathrm{mg} / \mathrm{dL})$.

Specimens from the $\mathrm{pH} 5.5$ group were immersed into artificial saliva regulated at $\mathrm{pH}$ 7.0, which was used previously, in order to cause remineralization (RM). Concentrations of $\mathrm{Ca}$ and $\mathrm{P}$ observed in the artificial saliva, which was replaced every two days, are shown in Table 2. As the result, all values of $\mathrm{Ca}$ concentration measured 5 times after two to 10 days after immersion were lower values than the value $1.73 \pm$ $0.44 \mathrm{mg} / \mathrm{dL}$ before immersion while showing no significant difference. Similarly, P concentration before immersion was $11.68 \pm 0.15 \mathrm{mg} / \mathrm{dL}$ showing no significant difference between values at each measurement.

Table 3 shows the comparison of values between ST, pH 7.0 and $\mathrm{pH} 5.5$ groups and the average HUVs of RM for each depth. The $\mathrm{pH}$ 5.5 group showed significantly lower values than the ST group only at a layer $0-150 \mu \mathrm{m}$ in depth $(\mathrm{p}<0.01)$. On the other hand, no significant difference was observed in the case of the $\mathrm{pH} 7.0$ group in values of any layer compared with those of the ST group. Significant difference was observed in the case of RM in values of all layers compared with ST, pH 5.5 and $\mathrm{pH} 7.0$ groups $(\mathrm{p}<0.01)$.

As a control group of RM, Table 4 shows the results of HUVs measured after immersing four specimens, of which HUVs had been measured after demineralization in ultrapure water regulated at $\mathrm{pH} 7.0$ for 5 days. There was no significant difference between the average HUV of each layer and values soon after demineralization (DM).

Table 1. Changes in the concentration of $\mathrm{Ca}$ and $\mathrm{P}$ in the artificial saliva $(\mathrm{mg} / \mathrm{dL})(\mathrm{n}=10)$

\begin{tabular}{cccccc}
\hline & \multicolumn{2}{c}{$\mathrm{pH7.0}$} & & \multicolumn{2}{c}{$\mathrm{pH} 5.5$} \\
\cline { 2 - 3 } \cline { 5 - 5 } $\begin{array}{c}\text { Before } \\
\text { immersion }\end{array}$ & $\mathrm{Ca}$ & $\mathrm{P}$ & & $\mathrm{Ca}$ & $\mathrm{P}$ \\
$\begin{array}{c}\text { After } \\
\text { immersion }\end{array}$ & $1.51 \pm 0.44$ & $11.68 \pm 0.15$ & & $2.80 \pm 0.18$ \\
\hline & & & \\
\hline
\end{tabular}

Table 2. Concentration of $\mathrm{Ca}$ and $\mathrm{P}$ in artificial saliva (RM) during remineralization (mg/ dL) $(\mathrm{n}=10)$

\begin{tabular}{lrccccc}
\multicolumn{2}{c}{ Before immersion } & 2days & 4days & 6days & 8days & 10 days \\
$\mathrm{Ca}$ & $1.73 \pm 0.44$ & $1.49 \pm 0.15$ & $1.55 \pm 0.15$ & $1.51 \pm 0.25$ & $1.39 \pm 0.25$ & $1.54 \pm 0.46$ \\
$\mathrm{P}$ & $11.68 \pm 0.15$ & $11.54 \pm 0.08$ & $11.58 \pm 0.26$ & $11.75 \pm 0.24$ & $11.67 \pm 0.32$ & $11.50 \pm 0.31$
\end{tabular}

Table 3. HUV comparison of different depth in each group $(n=10)$

\begin{tabular}{|c|c|c|c|c|}
\hline group/depth $(\mu \mathrm{m})$ & $0-150$ & $150-300$ & $300-450$ & $450-600$ \\
\hline ST & $6257 \pm 356$ & $5681 \pm 281$ & $5581 \pm 345$ & $5499 \pm 468$ \\
\hline $\mathrm{pH} 7.0$ & $6133 \pm 614$ & $5523 \pm 516$ & $5286 \pm 538$ & $5186 \pm 513$ \\
\hline $\mathrm{pH} 5.5$ & $5827 \pm 548$ & $5385 \pm 467$ & $5263 \pm 509$ & $5263 \pm 434$ \\
\hline RM & $6812 \pm 801$ & $6500 \pm 702$ & $6466 \pm 773$ & $6390 \pm 999$ \\
\hline
\end{tabular}

${ }^{*} p<0.01$

Table 4. HUV of the control group at the time of remineralization $(n=4)$

\begin{tabular}{ccccc}
\hline group $/$ depth $(\mu \mathrm{m})$ & $0-150$ & $150-300$ & $300-450$ & $450-600$ \\
\hline DM & $6110 \pm 619$ & $5993 \pm 509$ & $5909 \pm 448$ & $5926 \pm 391$ \\
RM & $6294 \pm 411$ & $6058 \pm 231$ & $5937 \pm 128$ & $5971 \pm 270$ \\
\hline
\end{tabular}

\section{Discussion}

\section{Changes in Ca and $P$ concentration in artificial saliva}

Mineral transport between enamel and saliva is caused by changes in mineral solubility resulting from changes in the $\mathrm{pH}$ of saliva [1]. More specifically, when the $\mathrm{pH}$ of resting saliva is a normal $\mathrm{pH}$ ranging from 6 to 6.5 , salivary minerals are saturated with respect to hydroxyapatite and mineral migration does not occur. However, if the secretion rate of saliva increases and the $\mathrm{pH}$ rises [8], mineral solubility in saliva decreases and dissolved minerals precipitate or are absorbed by enamel. On the other hand, in the case of the decrease in salivary secretion rate typified by xerostomia, salivary minerals become unsaturated with respect to hydroxyapatite (solubility increases), and minerals begin to be released into saliva [9]. Fosdic, et al. [1] and Ericsson [10] report that the $\mathrm{pH}$ around $\mathrm{pH} 5.5$ is the critical $\mathrm{pH}$. In the present study, experiments were conducted by adjusting the $\mathrm{pH}$ of artificial saliva to 5.5 in order to clarify the demineralization of enamel at the critical pH. Also, as for artificial saliva, that prescribed by ten Cate [7], which has been used in many remineralization studies, was used.

The results of this study are that in the case that enamel was immersed in artificial saliva at $\mathrm{pH} 7.0$, no statistically significant change was observed in the $\mathrm{Ca}$ and $\mathrm{P}$ concentrations in the artificial saliva after immersion, but that in the case of the specimen immersed in artificial saliva at $\mathrm{pH} 5.5$, a statistically significant increase was observed in the $\mathrm{Ca}$ and $\mathrm{P}$ concentrations in the artificial saliva. This suggests that minerals in the artificial saliva were saturated with respect to enamel at $\mathrm{pH} 7.0$, and that no statistically significant mineral migration occurred between them, whereas because at $\mathrm{pH} 5.5$, minerals in the artificial saliva were unsaturated with respect to enamel, minerals were released from the enamel to the artificial saliva.

After that, when the specimen immersed in the $\mathrm{pH} 5.5$ group was immersed in artificial saliva at $\mathrm{pH} 7.0$, the Ca concentration in artificial saliva measured every 2 days was lower than that before immersion. In this experiment, artificial saliva was replaced every 2 days in order to provide more fresh artificial saliva to the specimen. It is inferred that if immersion had been carried out with the same artificial saliva for more than two days, a statistically significant difference would have been observed in the Ca concentration between before and after immersion.

\section{Changes in mineral density in enamel}

Enamel contains many trace elements. Brudevold and Soremark [11] divided enamel into three layers from the surface layer to the inside, examined the concentration of trace elements by powdering each layer. They reported that $\mathrm{F}, \mathrm{Zn}, \mathrm{Pb}, \mathrm{Fe}, \mathrm{Sn}$ are highly concentrated in the surface layer, that $\mathrm{Sr}$ and $\mathrm{Cu}$ are almost evenly distributed throughout the three layers, and that $\mathrm{CO}^{2}, \mathrm{Mg}$ and $\mathrm{Na}$ are more highly concentrated in the deep layer. The fact that $\mathrm{F}$ and $\mathrm{Zn}$ are abundantly present in the layer where subsurface demineralization occurs means that even if demineralization occurs, these elements are in an environment in which they can be easily absorbed in the process of remineralization when the environment improves. When $\mathrm{F}$ ions are substituted in apatite crystals, stable crystals of fluoroapatite, $\mathrm{Ca}_{10}\left(\mathrm{PO}_{4}\right)_{6} \mathrm{~F}_{2}$, are formed. It is known that the acid resistance of fluoroapatite [12] increases sharply as the $\mathrm{F}$ content increases.

The results of this study were that when the mineral density in the region from the surface layer down to the depth of $600 \mu \mathrm{m}$ was examined in the ST group, the HUV was highest on the surface and decreased as it went deeper. This indicates that besides the minerals contained in enamel, the mineral density is higher in the enamel 
surface layer than in the deep layer because the enamel surface layer is constantly influenced by saliva, etc. [13]. This is the reason that clinically demineralization of enamel begins from the region under the surface layer where mineral density is lower than in the surface layer rather than from the surface layer with relatively good acid resistance.

Although we were unable to identify the minerals in this study, we were able to clarify the transition of mineral density from the surface layer to the deep layer for the first time by using micro CT.

Enamel repeats demineralization and remineralization daily due to changes in saliva $\mathrm{pH}$ in the oral cavity. The remineralization therapy is considered to increase its importance in dental clinic in the future. The results of the experiments in this study confirmed aspects of enamelsalivary mineral migration in initial demineralization. This seemed to be useful as basic data on the future remineralization therapy and the maturation of immature permanent teeth.

\section{References}

1. Fosdick LS, Starke AC (1939) Solubility of tooth enamel in saliva at various pH levels. J Dent Res 18:269-263.

2. Hafström-Björkman U, Sundström F, de Josselin de Jong E, Oliveby A, AngmarMånsson B (1992) Comparison of laser fluorescence and longitudinal microradiography for quantitative assessment of in vitro enamel caries. Caries Res 26:241-247.[Crossref]

3. Ando M, van der Veen MH, Schemehorn BR, Stookey GK (2001) Comparative study to quantify demineralized enamel in deciduous and permanent teeth using laser and lightinduced fluorescence techniques. Caries Res 35:464-470. [Crossref]
4. Huang TT, Jones AS, He LH, Darendeliler MA, Swain MV (2007) Characterisation of enamel white spot lesions using X-ray micro-tomography. J Dentistry 35:737-43. [Crossref]

5. Farah RA, Swain MV, Drummond BK, Cook R, Atieh M (2010) Mineral density of hypomineralised enamel. $J$ Dentistry 38:50-58. [Crossref]

6. Wong FS, Anderson P, Fan H, Davis GR (2004) X-ray microtomographic study of mineral concentration distribution in deciduous enamel. Arch Oral Biol 49:937-944. [Crossref]

7. ten Cate JM, Duijsters PPE (1982) Alternating demineralisation and remineralization of artificial enamel lesions. Caries Res 16:201-210.[Crossref]

8. Dawes C, Dong C (1995)The flow rate and electrolyte composition of whole saliva elicited by the use of sucrose-containing and sugar-free chewing-gums. Arch Oral Biol 40:699-705. [Crossref]

9. Silverstone LM (1977) Remineralization phenomena. Caries Res 11: 59-84. [Crossref]

10. Ericsson Y (1949) Investigations into the calcium phosphate equilibrium between enamel and saliva and its relation to dental caries. ActaodontScand 8 .

11. Brudevold F, Soremark R (1967) Chemistry of the mineral phase of enamel from structural and chemical organization of teeth. Edited by Miles AEW, Academic Press New York and London, 247-277.

12. Poulsen S, Larsen MJ (1975) Dental caries in relation to fluoride content in the primary dentition. Caries Res 9:59-65.[Crossref]

13. ten Cate JM, Larsen MJ, Pearce EIF, Fejerskov O (2008) Fluoride reactions in the ora environment. In Dental Caries, TheDisease and its Clinical Management ( $2^{\text {nd }}$ edition), Ole Fejerskov and Edwina Kidd (ed), BlakwellMunksgaard, Oxford, 225-226.

Copyright: $@ 2017$ Kurihara H. This is an open-access article distributed under the terms of the Creative Commons Attribution License, which permits unrestricted use, distribution, and reproduction in any medium, provided the original author and source are credited. 